\title{
Discussion of Design Innovations and Development Trend of Bedroom Furniture
}

\author{
Pan Xue, Wang Yangao, Zhong Siwen, Zhou zihang \\ College of Forestry, Sichuan Agricultural University \\ No.211, Huimin Road, Wenjiang District, Chengdu City , Sichuan, 611130 \\ hunter2011@foxmail.com
}

Keywords: Bedroom Furniture; Living Needs; Innovative Design

\begin{abstract}
Bedroom furniture is closely related to our daily life rest, which is designed to meet the people in their daily living life in practical, aesthetic, joy and other needs, but also by the rapid development of modern economy, culture and lifestyle of the new information society. In this paper, the bedroom in the home environment lifestyle research foundation, pointed out that matters bedroom furniture design should pay attention, and describes future innovation bedroom furniture design trends.
\end{abstract}

\section{The Design Innovation of Bedroom Furniture}

With the development of society, people's material and cultural living standards improve, and people requirements are also rising on bedroom home environment. Design the suitable bedroom furniture with a comfortable environment, help people learn, work, live and rest. Under the new economic era of innovative design background bedroom furniture, we must first take into account the needs of users, and design a different demand patterns with reference to different people live. For example: a double bedroom primarily for couples living room, double bed two bedside tables general configuration. However, it is worth noting that at the same time taking into account the specificity, but also the general requirements, such as: a set of bedroom furniture typically includes multi-door wardrobe, dresser and dressing stool and so on. Bedroom home environment for the overall atmosphere of the innovative design, it should take into account all aspects of the factors.

Modern bedroom living already the product TV cabinets, computer tables and other modern life moved in, bringing the technological development of the emergence of these new types of furniture, but also brought unprecedented challenges bedroom furniture innovative design. "Ancient Methods and Modern, of the old for the new," emphasizes the innovative design of Chinese bedroom furniture, face pressure this innovative claim, furniture designers often lack inspiration. In fact, all the experience, ideas, understanding and perception of life always comes from practice. Faced with new challenges, designers should calmly analyze discrimination, deep into life, appreciate life, subtle changes in lifestyle, the rapid capture of information and inspiration, in accordance with modern furnishings living space, life needs to bedroom furniture inadequate modified adjusted trend of the times, to make it more perfect [1].

\section{The Considerations of Bedroom Furniture Design}

Overall, the bedroom furniture should be robust, simple, practical, and rest of the people feel a stable spiritual, warm feeling. Bedroom furniture, decorative position, decorative forms, decorative techniques especially decorative dimension size will give people a completely different feeling, so right bedroom furniture scale will bring beauty to enjoy. People like concise, honest, rounded, classic, elegant style, thus making furniture decorated with particular attention to the retractable linear proportion and size to width by depth, emergency relief tight, flat handle effectively increase the level of these subtle soft feel of furniture, retractable and can't be too abrupt transition, note collection points and linear smooth visually graceful curves simple linear combination ${ }^{[2]}$. 
Determine the basic characteristics of furniture styling lines of the design. Horizontal surface design furniture can be expressed, gives a stretch, peaceful, stable results; vertical line gives a dignified, upright sense; curve showing the speed, power and flexibility; slash scattering gives rise and changes sense of insecurity and so on. For example: to angle furniture designed sleek feel, cabinet handle made of rounded shape, avoid the use of the bedroom furniture forms stiff, rigid lines, the use of some smooth curve, people psychologically to be quiet, soft feeling. Therefore, furniture designers generally use less with or without a slash in the bedroom furniture style, and appropriate use of some curves to bring elegance bedroom, gentle, plump, soft feel. Determine the basic characteristics of furniture style are lines of the design. Horizontal surface design furniture can be expressed, gives a stretch, peaceful, stable results; vertical line gives a dignified, upright sense; curve showing the speed, power and flexibility; slash scattering gives rise and changes sense of insecurity and so on. For example: to angle furniture designed sleek feel, cabinet handle made of rounded shape, avoid the use of the bedroom furniture forms stiff, rigid lines, the use of some smooth curve, people psychologically to be quiet, soft feeling. Therefore, furniture designers generally less with or without a slash in the bedroom furniture style, and appropriate use of some curves to bring elegance bedroom, gentle, plump, soft feel

At the same time, pay attention to symbols design features bedroom furniture. Chinese people love a long history of cultural traditional patterns, like in furniture design decorative patterns on modeling elements symbols. For example in the furniture engraved "slim" character pattern doorknob handle, beautiful graphics and characters to handle the bronze doors with shine, which means blending "wealth and longevity", "happiness and longevity," so that people taste the charm of traditional culture. These "symbol" is that people pay attention to the point of embellishment bedroom design, and designers of these "symbols" clever use of modern furniture design, not just a decoration, decoration needs but also cultural heritage and beyond. In fact, the use of symbols is to find a meeting point between the traditional and modern furniture design, in order to meet the needs of the human subconscious on the senses ${ }^{[3]}$.

\section{The Future Innovation Design Trend}

For the modern people under the more and more pressure, bedroom is not just a shelter from the wind and rain, where cultivation of body and mind, it is the fate of people weary soul, then experience the joie de vivre of a safe haven, so bedroom furniture innovation should be designed with human home environment and the demand for lifestyle combined. More and more scholars believe that: generous fashion, simplicity of application, harmonious and comfortable modern bedroom furniture design must be integrated into the factors, but also the home owner attitude towards life and taste reflected ${ }^{[4]}$.

Bedroom furniture should consider combining innovative design and new materials and furniture, bedroom furniture material is the basis for the design, it is with people, products, environment interact to promote the design and development of furniture together. The materials have been used in the furniture is very rich, metal, plastic, multi-layer plywood, particleboard, medium density fiberboard, honeycomb composite panels, OSB, etc., glass furniture transparent, pure, exquisitely carved; wood furniture and fresh, fascinating and charming, each material in the shape of different historical periods innovative home furniture has brought unprecedented power and charm, it has greatly enriched our furniture. With the high-tech and materials science applications in the furniture design industry in recent years, the popularity of low-carbon environmental theme, eco-friendly materials sought after by many designers, environmental, ecological and return to nature become a modern innovative design of bedroom furniture. Ecological furniture is built on people-oriented, based on the control of natural resources, more use of composite materials can be recycled to create an environment conducive to use, comfortable and healthy furniture design materials, realization request and get the natural return to nature the balance between, has become an inevitable trend. How to combine modern trends of new materials, used in the innovative design of the bedroom furniture, various furniture designers need to consider the key. Fig.1 shows the future innovation design trends principle. 


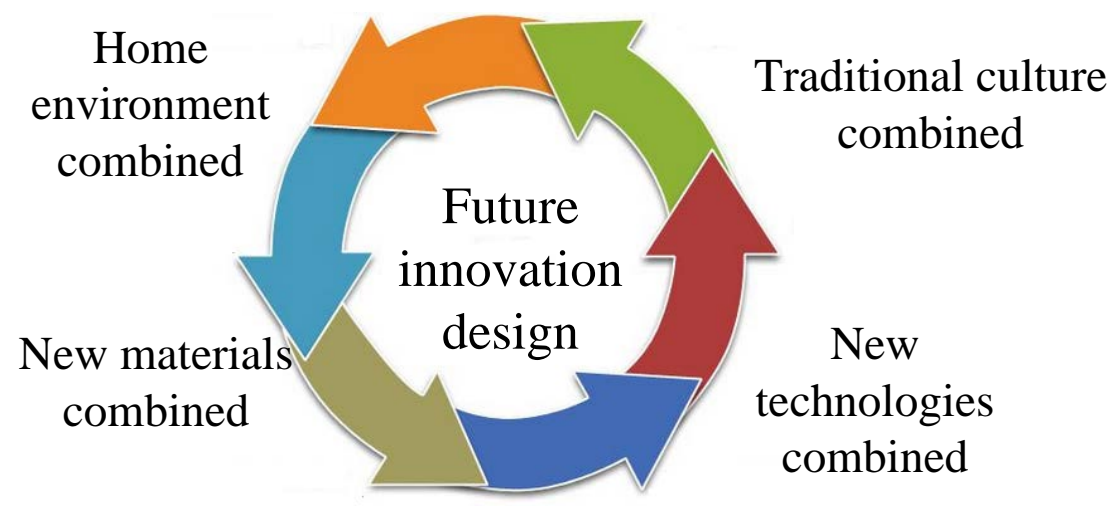

Fig. 1.The future innovation design trends principle

Innovative bedroom furniture and furniture design should consider a combination of new technologies, technical processes is an important chapter of bedroom furniture design. Veneer technology, coating technology, bending technology, casting technology, etc., which are important means of furniture design to be carried out. Different technological applications will have the same kind of material distinct texture performance, and ultimately affect the overall effect of furniture products. Compared with traditional furniture production, the production of modern furniture assembled late to change the pre-assembled as a direct reflection of the revolutionary transformation of production design ideas. The drill, iron, sawing, gouging and machining tools are greatly enhancing the production, processing capacity and product processing accuracy, based on the final application of artificial board furniture standardized, universal, serialized production. After bedroom furniture design, using modern high efficiency equipment and technology is an inevitable trend, cleverly combined with modern industrial technology and design art will provide greater innovation and development bedroom furniture design ${ }^{[5]}$.

Bedroom furniture innovative design should consider the combination of traditional culture, a lot of people's hearts have rich traditional Chinese complex, the essence of national culture by human love, in succession on the basis of traditional Chinese culture, added bedroom home-style fashion elements more and more popular. Therefore, I believe the innovative design of furniture include: the modern home health, then a new culture and a new traditional style, the traditional decorative techniques were refined sublimation, adding innovative and stylish design elements, the innovative design of future bedroom furniture a major trend. Continuation of cultural heritage and the cultural emphasis on keeping with regional, national characteristics, design heritage and continue to emphasize having geographical, ideas and methods to deal with the issue of national identity design, at the same time, reasonable arrangements for bedroom furniture modeling decorative elements bedroom furniture priority future innovation and development, furniture designers in the pursuit of perfection, harmony, perfection, while Heaven design, but also to grasp the complex and orderly, diverse and unified modern art.

\section{Conclusions}

At present, bedroom furniture style is not only penetrate the Chinese traditional culture, but also full of a deep national consciousness. With the development of economy and technology, the bedroom furniture design has also ushered in a new period of development. Based on the analysis bedroom furniture innovation point of attention on the future of the innovative design trends to predict, it is a traditional furniture design analysis conducted Recognition. Modern bedroom furniture innovative use of new technologies, new materials, new technology, etc. will be formed with the same strain of traditional design but step closer to a new style, full use of modern computer technology, information and other resources with the times, give the people of bedroom design more choice and use of space. Bedroom furniture designers focus on the daily life of personal experience, starting from the details, starting from the function, maintain a high degree of 
consistency with the new materials, new technologies, create more beautiful shape, materials, environmental protection, rational function, colorful new bedroom furniture form.

\section{References}

[1] Mo Wo-jia. Research on Modeling Analysis and Application of Ming-style chair, Jiangnan University, 2006, 5: 31- 49.

[2] Tang Kai-jun. Process of formation of furniture styles, Beijing Forestry University, 2004, 6, 216.

[3] He Xiu-chuan. Creative Design Method of New Chinese furniture, Beijing Institute of Technology (Social Sciences), 2007, 6.

[4] Hu Fei, Yang Rui, et al. Design symbols and product semantics: Theory, Methods and Applications, the China Construction Industry Press, 2012: 138-144.

[5] Liu Xin Yan. Innovation of Chinese furniture design system, Central South University of Forestry and Technology, 2006. 